\title{
Prevalence and deteminants of obesity in Spanish children and young people
}

\author{
Lluis Serra-Majem ${ }^{1}$, Javier Aranceta Bartrina ${ }^{2}$, Carmen Pérez-Rodrigo ${ }^{2}$, Lourdes Ribas-Barba ${ }^{3}$ and \\ Alfonso Delgado-Rubio 4 \\ ${ }^{1}$ Department of Clinical Sciences, University of Las Palmas de Gran Canaria, PO Box 55, E-0 35080 Las Palmas de Gran \\ Canaria, Spain \\ ${ }^{2}$ Community Nutrition Unit, Department of Public Health, Bilbao, Spain \\ ${ }^{3}$ Unit for Research in Community Nutrition, Scientific Park, Barcelona University, Barcelona, Spain \\ ${ }^{4}$ Department of Pediatrics, University of the Basque Country, Bilbao, Spain
}

\begin{abstract}
Prevalence estimates of obesity in a national random sample of Spanish children and young people are presented in this paper, defined by age- and sex-specific BMI national reference standards for the 85th percentile (overweight) and 97th percentile (obesity), as well as by Cole et al. criteria. A random sample of 3534 people, aged 2-24 years, was interviewed between 1998 and 2000. The study protocol included personal data, data on education and socioeconomic status (SES) for the family, dietary assessment, anthropometric measurements and physical activity. The prevalence of obesity was $13.9 \%$ (95\% CI 12.7, 15.1) considering Spanish reference standards as cut-offs. Obesity was significantly higher in boys (15.6\%) than in girls (12\%). The highest values were observed between 6 and 13 years of age. Using Cole's cut-offs, the estimated prevalence of obesity was $6.3 \%$ (95\% CI 5.4, 7.5) with a similar pattern to that previously described by sex. Regarding sociodemographic factors, sex, age group, region, size of locality of residence, mother's level of education and family SES level were significant predictors for obesity in children and adolescents under 14 years. Among young people, the main sociodemographic predictors for obesity were geographical region and family SES level. Odds ratio for obesity was 1.27 for those with a more frequent consumption of buns, cakes and snacks, and 1.71 for those with more frequent consumption of sugared drinks. Adequate consumption of fruit and vegetables, usually having breakfast and regular sports practice had a protective effect. The available data show that obesity in Spain is a public health issue given its magnitude and increasing trends. Among Spanish children and young people, those at prepubertal age, particularly boys, can be identified as a group at higher risk for overweight and obesity, particularly children from lower SES families.
\end{abstract}

Children: Adolescents: Obesity: Overweight: Prevalence: Determinants: Population study

Obesity has been recognized as a public health problem in developed countries. In particular, obesity in childhood and adolescents is a major concern. Physical and psychosocial problems are among the short-term adverse effects and associated risks from obesity in the early stages of life (World Health Organization, 2000). Longitudinal studies suggest that obesity after 3 years of age is associated in the long term with a greater risk of obesity in adults, increased morbidity and mortality, persistence of associated metabolic disorders, as well as increased risk for CVD and some types of cancer (Powers et al. 1997; Freedman et al. 1999; World Health Organization, 2000).

Considering the limitations in the available data, it seems more likely that obese children will be obese adults in comparison with normal weight children, although paradoxically most obese adults at the present time were not obese children. Obesity in the second decade of life is a predictive factor for adult obesity (Vanhala et al. 1998; Guo \& Chumlea, 1999; Wabitsch, 2000).

Changes in environmental factors, such as dietary habits and a sedentary life-style, and their interaction on genetic susceptibility have been described as causes for the rise in the prevalence of obesity over the last decades (Maffeis et al. 1998; Maffeis, 2000). School years and adolescence are crucial stages for the development of healthy eating habits and other life-styles that persist in later life (Birch \& Fisher, 1998).

In the 1980s, the PAIDOS'85 study estimated the prevalence of obesity on a national random sample of Spanish children (Bueno, 1985). Since then, several studies in Spain have contributed estimates on local and regional samples or limited age groups based on measured body weight and height. The Cuenca study estimated the prevalence of obesity among 307 children aged 9-12 years in this Spanish city in 1992 who were followed-up for 6 years (Martínez Vizcaíno et al. 2002). Other authors have reported data on local and regional samples of school-aged children and convenience samples of adolescents from several cities in the country (Rios et al. 1999; Moreno et al. 2000; Garces et al. 2005).

In the present paper, the prevalence of obesity and determinant factors are described on a Spanish national sample of children and young people aged 2-24 years, the enKid Study, based on measured body weight and height. 


\section{Population and methods}

The enKid Study is a cross-sectional study carried out on a national random sample of the Spanish population aged 2-24 years. Sampling procedures and response rates have been described elsewhere (Serra-Majem \& Aranceta Bartrina, 2000; Serra-Majem et al. 2003). The study protocol considered date of birth, sex, level of education of the mother and father, socioeconomic status (SES) data for the family, birth weight and infant feeding practices. Dietary intake was assessed by means of a $24 \mathrm{~h}$ recall and a quantitative food frequency questionnaire. In $25 \%$ of the sample a second $24 \mathrm{~h}$ recall was collected. In order to avoid seasonal and weekly variations, dietary recalls were scattered throughout the year, including all days of the week. Information was collected during a personal interview at the home of the interviewee, in the presence of the mother or person responsible for the family diet in children under 13 years of age.

Specific questionnaires were designed to collect data on smoking habits and alcohol use. Physical activity was assessed by means of a detailed frequency questionnaire, including weekdays and weekends. Usual physical activity in school, method of going to and from school, sport club activities as well as leisure-time physical activity and sports practice were considered in the questionnaire.

\section{Anthropometric measurements}

The following measurements were assessed: body weight, height, BMI (weight $/$ height $^{2}$ ), waist and hip circumference, waist: hip ratio and diameter of the elbow. The measurements were taken in underwear, no socks, at the home of the interviewee using electrical scales to the nearest $100 \mathrm{~g}$. Height was measured using a Kawe stadiometer to the nearest $1 \mathrm{~mm}$. Circumferences were measured with inextensible metric tapes according to standardized protocol (Lohman et al. 1988) to the nearest $1 \mathrm{~mm}$.

Overweight and obesity were defined using as criteria the value of BMI-specific percentiles for age and sex in the reference population (Hernández et al. 1988). Cut-off for overweight was 85th percentile and for obesity the 97th percentile (Rolland-Cachera et al. 2001). Overweight and obesity were also defined according to the criteria suggested by Cole et al. (2000), recommended by the International Obesity Task Force.

Fieldwork was carried out by 43 dietitian experts who followed a training period and standardization of criteria before beginning the work (1998-2000).

The association between obesity and determinant factors considered was analysed through multiple binomial logistic regression, following a step-wise method. Different models were fitted for children under 14 years and young people. Adjusted odds ratios (OR) and 95\% CI are presented for both age groups. The data were analysed using SPSS (version 12.0; SPSS Inc., Chicago, IL, USA).

\section{Results}

Table 1 shows prevalence and $95 \%$ CI estimates by age group and sex using Spanish reference standards and Cole et al. cutoffs. The prevalence of obesity for this age group in Spain was estimated at $13.9 \%(95 \%$ CI $12.7,15.1)$ and $12.4 \%$ for overweight, considering Spanish reference stadards as cut-offs. Altogether, overweight and obesity involve $26.3 \%$ (95\% CI $24.8,27.8$ ) of the sample. Obesity was significantly higher in boys $(15.6 \%)$ than in girls $(12 \%)$. The highest values were observed between 6 and 13 years of age. Using Cole's cut-offs, the estimated prevalence of obesity was $6.3 \%$ $(95 \%$ CI $5.4,7.5)$ with a similar pattern to that previously

Table 1. Prevalence of obesity in Spanish children and young population (2-24 years) by age group and sex (the enKid Study) according to the Spanish reference standards (85th and 97 th percentiles) ${ }^{*}$ and using the criteria suggested by Cole et al. $\dagger$

\begin{tabular}{|c|c|c|c|c|c|c|}
\hline \multirow[b]{2}{*}{ Age group } & \multirow[b]{2}{*}{ Sex } & \multirow[b]{2}{*}{$n$} & \multicolumn{2}{|c|}{ Spanish reference standards* } & \multicolumn{2}{|c|}{ Cole et al. definition ${ }^{\dagger}$} \\
\hline & & & $\begin{array}{c}\text { Obesity } \\
(\mathrm{BMI} \geq 97 \text { th percentile }) \\
\%(95 \% \mathrm{Cl})\end{array}$ & $\begin{array}{c}\text { Total overweight } \\
\text { (BMI } \geq 85 \text { th percentile) } \\
\%(95 \% \mathrm{Cl})\end{array}$ & $\begin{array}{c}\text { Obesity } \\
\%(95 \% \mathrm{Cl})\end{array}$ & $\begin{array}{c}\text { Total overweight } \\
\%(95 \% \mathrm{Cl})\end{array}$ \\
\hline \multirow[t]{3}{*}{$2-5$ years } & Total & 385 & $11 \cdot 1(7 \cdot 9,14 \cdot 3)$ & $21 \cdot 0(16 \cdot 8,25 \cdot 2)$ & $10 \cdot 4(7 \cdot 8,13 \cdot 8)$ & $27 \cdot 0(22 \cdot 0,32 \cdot 6)$ \\
\hline & Boys & 195 & $10 \cdot 8(6 \cdot 4,15 \cdot 2)$ & $20.1(14.4,25 \cdot 8$ & $8.3(5.9,11.5)$ & $21.9(16 \cdot 0,29 \cdot 2)$ \\
\hline & Girls & 190 & $11.5(6 \cdot 8,16 \cdot 2)$ & $21.9(15.8,28.0)$ & $12 \cdot 7(8 \cdot 1,19 \cdot 4)$ & $32 \cdot 6(24.9,41.3)$ \\
\hline & Boys & 211 & $21 \cdot 7(16 \cdot 1,27 \cdot 3)$ & $37.7(31 \cdot 1,44 \cdot 3)$ & $12 \cdot 1(7 \cdot 3,19 \cdot 4)$ & $37.9(31.2,45 \cdot 0)$ \\
\hline & Girls & 212 & $9 \cdot 8(5 \cdot 8,13 \cdot 8)$ & $22.9(17 \cdot 2,28 \cdot 6)$ & $8 \cdot 6(5 \cdot 1,14 \cdot 1)$ & $32 \cdot 4(24 \cdot 7,41 \cdot 1)$ \\
\hline \multirow[t]{3}{*}{$10-13$ years } & Total & 567 & $16 \cdot 6(13 \cdot 5,19 \cdot 7)$ & $31 \cdot 2(27 \cdot 3,35 \cdot 1)$ & $4.7(3.5,6 \cdot 2)$ & $27 \cdot 1(24 \cdot 1,30 \cdot 3)$ \\
\hline & Boys & 281 & $21.9(17 \cdot 0,26 \cdot 8)$ & $41.9(36 \cdot 1,47 \cdot 7)$ & $6 \cdot 6(5 \cdot 1,8 \cdot 5)$ & $32 \cdot 8(29 \cdot 1,36 \cdot 7)$ \\
\hline & Girls & 286 & $10.9(7.2,14.6)$ & $20 \cdot 0(15 \cdot 3,24 \cdot 7)$ & $2 \cdot 6(1.7,3 \cdot 9)$ & $21 \cdot 0(18 \cdot 1,24 \cdot 3)$ \\
\hline \multirow[t]{3}{*}{$14-17$ years } & Total & 682 & $12.5(10.0,15.0)$ & $21.8(18.7,24.9)$ & $6.5(4.9,9.0)$ & $21.9(18.5,25.9)$ \\
\hline & Boys & 337 & $15 \cdot 8(11.9,19 \cdot 7)$ & $26.2(21.5,30.9)$ & $10 \cdot 0(6 \cdot 8,14 \cdot 4)$ & $30.7(26.2,35.6)$ \\
\hline & Girls & 345 & $9 \cdot 1(6 \cdot 0,12 \cdot 2)$ & $17 \cdot 1(13 \cdot 1,21 \cdot 1)$ & $2 \cdot 8(1.9,4 \cdot 2)$ & $12 \cdot 7(9 \cdot 3,17 \cdot 2)$ \\
\hline \multirow{2}{*}{$18-24$ years } & Boys & 605 & $12 \cdot 6(9.9,15 \cdot 3)$ & $27.5(23.9,31 \cdot 1)$ & $5.9(4.2,8.4)$ & $27.4(23.7,31.4)$ \\
\hline & Girls & 872 & $14.9(12 \cdot 5,17 \cdot 3)$ & $26 \cdot 2(23 \cdot 3,29 \cdot 1)$ & $2 \cdot 0(1.5,2 \cdot 8)$ & $11.9(9.9,14.2)$ \\
\hline \multirow[t]{3}{*}{ Total } & Total & 3534 & $13 \cdot 9(12 \cdot 7,15 \cdot 1)$ & $26 \cdot 3(24 \cdot 8,27 \cdot 8)$ & $6.3(5.4,7.5)$ & $24 \cdot 4(22 \cdot 3,26 \cdot 6)$ \\
\hline & Boys & 1629 & $15 \cdot 6(13.8,17.4)$ & $29.9(27 \cdot 7,32 \cdot 1)$ & $7.9(6 \cdot 6,9 \cdot 6)$ & $29.5(27.1,31.9)$ \\
\hline & Girls & 1905 & $12.0(10.5,13.5)$ & $22.5(20 \cdot 6,24.4)$ & $4.6(3.4,6 \cdot 2)$ & $19 \cdot 0(16 \cdot 2,22 \cdot 2)$ \\
\hline
\end{tabular}

*Hernández et al. (1988).

${ }^{\dagger}$ Cole et al. (2000). 
described by sex (7.9\% boys; $4.6 \%$ girls) and age groups. Overweight and obesity according to Cole's criteria affected $24.4 \%$ of the sample (95\% CI 22.3, 26.6).

Table 2 shows predictors of obesity in Spanish children and adolescents in the enKid Study. Regarding sociodemographic factors, sex, age group, region, size of locality of residence, mother's level of education and family SES level were significant predictors for obesity in children and adolescents under 14 years. Prevalence OR for obesity was 1.95 (95\% CI $1.14,2.46)$ in boys in relation to girls. OR was $1.47(95 \%$ CI $1.14,1.88$ ) for the age group $6-9$ years in relation to the younger ones. The highest prevalence of obesity and overweight was observed in the Canary Islands $(O R=2.69)$ and southern regions $(\mathrm{OR}=1.78)$, in both sexes. Among children and adolescents under 14 years, the prevalence of obesity was higher in those living in towns and cities compared with children living in rural areas $(\mathrm{OR}=1 \cdot 19)$.

The prevalence of obesity was higher in boys whose parents had low education, especially if the mother had a low cultural level. OR for prevalence of obesity was 1.25 (95\% CI 1.03 , 1.67). Occupation of the mother did not enter in the model. The prevalence of obesity was higher in boys and girls from low-SES families $(\mathrm{OR}=1.27)$ compared with higher SES.

Among young people, the main sociodemographic predictors for obesity were geographical region, with an OR of 1.15 (95\% CI $0.83,1.47)$ for the Canary Islands in relation to the central region of the country, and family SES level. OR for obesity in girls was 0.98 (95\% CI 9.79, 1.99) in relation to boys in this age group.

For children under 6 years, weight at birth and breastfeeding practices also entered into the model. Prevalence of obesity was significantly higher among children who recorded birth weights over $3500 \mathrm{~g}$ in comparison with those who recorded a birth weight below $2500 \mathrm{~g}$. Children who were breastfed for 3 months or more showed a lower prevalence of obesity than those who were not breastfed.

At a second step, life-styles regarding dietary practices and physical activity were included as predictors in the model, adjusted for age, sex, geographical region, mother's educational level and family SES level. Regular breakfast consumption, inadequate consumption of buns, cakes, snacks and sugared drinks and consumption of fruit and vegetables were entered into the model, as well as time spent on sedentary activities such as television watching, computer use or video games, and frequency of practising sport.

Likelihood of being obese was higher among those with more frequent usual consumption of buns, cakes, snacks $(\mathrm{OR}=1.27)$ and sugared drinks $(\mathrm{OR}=1.71 ; 95 \% \mathrm{CI} 1.26$, 2.54). Adequate consumption of fruit and vegetables had a protective effect. For those who usually had less than two portions of fruit and vegetables OR was 2.12 (95\% CI 1.60, 3.02) compared with those having five or more. Having breakfast usually had a protective effect as well $(\mathrm{OR}=0.73)$.

OR for the prevalence of obesity was 1.68 (95\% CI $1 \cdot 18$, $2 \cdot 88$ ) for boys and girls who spent more than $2 \mathrm{~h}$ daily watching television in comparison with those who spent less time. Regular sports practice had a protective effect $(\mathrm{OR}=0.64)$.

Among young people (14-24 years), the prevalence of obesity was higher in smokers than non-smokers, in boys and girls alike. Frequent consumption of buns, snacks and sugared drinks were entered as predictors in the model, adjusted for sex, age, geographical region and family SES level. Higher consumption of fruit and vegetables and regular sports practice had a protective effect in young Spanish people.

\section{Discussion}

The enKid Study, to our knowledge, is the first cross-sectional study carried out on a national random sample of Spanish children and young people, including subjects from a wide age range (2-24 years) and individual measured body weight and height following a standardized protocol. The study design, the different questionnaires used and adequate training of fieldwork staff were carefully designed in order to ensure reliable and valid data. Quality control mechanisms were established both at the preparatory stage and during data collection.

In this study, different prevalence rates were obtained depending on the criteria used to define overweight and obesity. According to Spanish standards, the average prevalence of obesity in this age group of Spanish people is $13.9 \%$ (Serra-Majem et al. 2003). However, when using Cole et al. criteria, the global estimate is half of this figure $(6 \cdot 3 \%)$. Nevertheless, overweight and obesity follow a similar distribution pattern by age group, sex and other sociodemographic characteristics when using either criteria. This fact raises the issue for the need to clarify the most suitable criteria to define obesity when comparing data, both for international comparison purposes and when looking for trends within the same population (Flegal et al. 2001).

In the Cuenca study, a city in central Spain, Martínez Vizcaíno et al. (2002) reported prevalence for overweight of $26.6 \%$ and for obesity of $3.9 \%$ in a sample of 9-12-year-old children according to Cole et al.'s criteria, but no significant differences by sex. These figures are consistent with the estimates for the whole country in the enKid Study when using the same criteria for this age group, $22.45 \%$ for overweight and $4.7 \%$ for obesity. However, it is interesting to note that in the enKid Study significant differences in the prevalence of obesity across regions were identified. Furthermore, geographical region was a predictor for obesity, as well as sex, with an OR of 1.95 for boys compared with girls.

The follow-up of the Cuenca study estimated a relative risk of 2.9 (95\% CI 2.21, 4.04) for overweight children at baseline to be overweight or obese after a 6-year follow-up. Prevalence trends for overweight and obesity were also analysed by Moreno et al. (2000) in the region of Aragon, in the centreeast of the country, in school-aged children between 1985 and 1995. They reported a steady increase in the prevalence of overweight, particularly in boys. Furthermore, obese children in 1985 were more obese in 1995.

In the Child and Adolescent Trial for Cardiovascular Health in the USA, Dwyer et al. (1998) investigated predictors for obesity among 9-11-year-olds during a 2-year follow-up. Being obese at baseline, study site, race and male sex were predictors of obesity in this study.

Comparison of results in the enKid Study and data from a population study carried out in the mid-1980s, the PAIDOS study, show an increasing trend for obesity in Spain comparable to that reported in other countries such as France or Switzerland (Deheeger et al. 2002). 
Ll. Serra-Majem et al.

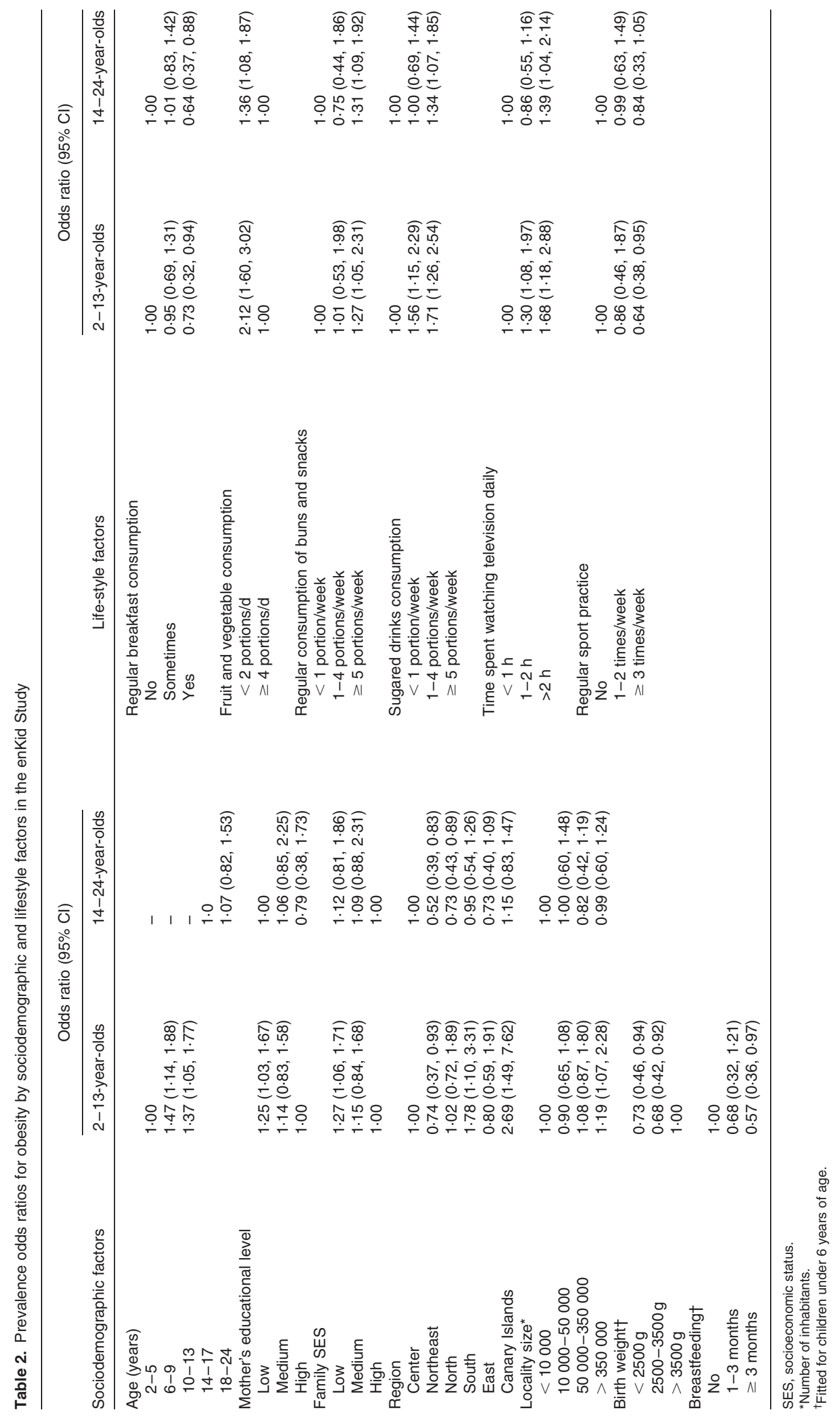


The estimated prevalence of obesity in the enKid Study is among the highest rates in European countries, as shown by data gathered by the expert group on childhood obesity of the International Obesity Task Force (Lobstein et al. 2004). It is noteworthy that the southern European countries in the Mediterranean region are those showing the highest figures along with the UK and the USA, compared with northern European countries, particularly Scandinavian countries.

Different studies have investigated sociodemographic, lifestyle and environmental determinant factors for obesity among children. No breastfed infants have been reported to be more likely to be obese children (Hediger et al. 2001; Arenz et al. 2004). A sedentary lifestyle, particularly spending more than $3 \mathrm{~h}$ a day watching television (Gortmaker et al. 1996), a high consumption of sugared drinks and fruit juices (Ludwig et al. 2001), a high fat intake (Livingstone, 2000) and inadequate consumption of fruit and vegetables (Epstein et al. 2001) have all been identified as determinant factors for obesity. This was the case in the enKid Study as well.

Results from the Health Behaviour in School-aged Children study, supported by WHO and carried out periodically in eleven countries around the world, highlight two key facts. On the one hand, reported consumption of fruits and vegetables in Spanish children and adolescents is among the lowest in Europe. On the other hand, physical activity and sports practice are also among the lowest in Spain, while children and young people in Scandinavian countries are more active (Currie et al. 2004). Results from the Pro Children study, a cross-sectional study performed in 10-12-year-old children in nine European countries, show a similar pattern for the consumption of fruit and vegetables (Yngve et al. 2005).

Available data show that obesity in Spain is a public health issue for its magnitude and increasing trends. Among Spanish children and young people, those at prepubertal age, particularly boys, can be identified as a group at higher risk for overweight and obesity, especially children from lower SES families.

Inspired by the WHO Global Strategy on Nutrition and Physical Activity (World Health Organization, 2004), the Spanish Ministry of Health launched the National Strategy for Nutrition, Physical Activity and Obesity with the aim of planning monitoring and prevention actions to face the problem in the country (Agencia Española de Seguridad Alimentaria, 2005). Establishing a monitoring system with comparable data at a national level, which is useful for international comparisons as well as identifying key determinant factors, particularly those which can be modified, is desirable when planning such preventive policies.

\section{References}

Agencia Española de Seguridad Alimentaria (2005) Estrategia NAOS. Invertir la Tendencia de la Obesidad. Estrategia Para la Nutrición, Actividad Física y Prevención de la Obesidad. Madrid: Ministerio de Sanidad y Consumo.

Arenz S, Ruckerl R, Koletzko B \& von Kries R (2004) Breast-feeding and childhood obesity - a systematic review. Int $J$ Obes Relat Metab Disord 28, 1247-1256.

Birch L \& Fisher J (1998) Development of eating behaviors among children and adolescents. Pediatrics 101, Suppl., 593-594.
Bueno M \& Grupo PAIDOS'84 (1985) PAIDOS'84. Estudio Epidemiológico Sobre Nutrición y Obesidad Infantil. Proyecto Universitario. Madrid: DANONE.

Cole TJ, Bellizzi MC, Flegal KM \& Dietz WH (2000) Establishing a standard definition for child overweight and obesity worldwide: international survey. BMJ 320, 1240-1243.

Currie C, Roberts C, Morgan A, Smith R, Settertobulte W, Samdal O \& Rasmussen VB (eds) (2004) Young People's Health in Context. Health Behaviour in School-aged Children (HBSC) Study: International Report from the 2001/2002 Survey. Health Policy for Children and Adolescents. no. 4. Copenhagen: World Health Organization Regional Office for Europe.

Deheeger M, Bellisle F \& Rolland-Cachera MF (2002) The French longitudinal study of growth and nutrition: data in adolescent males and females. J Hum Nutr Diet 15, 429-438.

Dwyer J, Stone EJ, Yang M, et al. (1998) Predictors of overweight and overfatness in a multiethnic pediatric population. Am J Clin Nutr 67, 602-610.

Epstein LH, Gordy CC, Raynor HA, Beddome M, Kilanowski CK \& Paluch R (2001) Increasing fruit and vegetable intake and decreasing fat and sugar intake in families at risk for childhood obesity. Obes Res 9, 171-178.

Flegal KM, Ogden CL, Wei R, Kuczmarski RL \& Johnson CL (2001) Prevalence of overweight in US children: comparison of US growth charts from the Centers for Disease Control and Prevention with other reference values for body mass index. Am J Clin Nutr 73, 1086-1093.

Freedman DS, Dietz WH, Srinivasan SR \& Berenson GS (1999) The relation of overweight to cardiovascular risk factors among children and adolescents: the Bogalusa Heart Study. Pediatrics 103, 1175-1182.

Garces C, Gutierrez-Guisado J, Benavente M, et al. (2005) Obesity in Spanish schoolchildren: relationship with lipid profile and insulin resistance. Obes Res 13, 959-963.

Gortmaker SL, Must A, Sobel AM, Peterson K, Colditz GA \& Dietz WH (1996) Television viewing as a cause of increasing obesity among children in the United States. Arch Pediatr Adolesc Med 150, $356-362$

Guo SS \& Chumlea WC (1999) Tracking of body mass index in children in relation to overweight in adulthood. Am J Clin Nutr 70, Suppl. 1, 145S-148S

Hediger ML, Overpeck MD, Kuczmarski RJ \& Ruan WJ (2001) Association between breastfeeding and overweight in young children. JAMA 285, 2506-2507.

Hernández M, Castellet J, García M, et al. (1988) Curvas de Crecimiento. Instituto de Investigación Sobre Crecimiento y Desarrollo, Bilbao: Fundación Orbegozo.

Livingstone B (2000) Epidemiology of childhood obesity in Europe. Eur J Pediatr 159, Suppl. 1, 14-34.

Lobstein T, Baur L \& Uauy R for the IASO International Obesity Task Force (2004) Obesity in children and young people: a crisis in public health. Obes Rev 5, Suppl. 1, 4-85.

Lohman TG, Roche AF \& Martorell R (eds) (1988) Anthropometric Standardization Reference Manual. Champaign, IL: Human Kinetics Books.

Ludwig DS, Peterson KE \& Gortmaker SL (2001) Relation between consumption of sugar-sweetened drinks and childhood obesity: a prospective, observational analysis. Lancet 357, 505-508.

Maffeis C (2000) Aetiology of overweight and obesity in children and adolescents. Eur J Pediatr 159, Suppl. 1, S35-S44.

Maffeis C, Talamini G \& Tato L (1998) Influence of diet, physical activity and parents' obesity on children's adiposity: a four year longitudinal study. Int J Obes Relat Metab Disord 22, 758-776.

Martínez Vizcaíno F, Salcedo Aguilar F, Rodríguez Artalejo F, Martínez Vizcaíno V, Domínguez Contreras ML \& Torrijos Regidor R (2002) Prevalencia de obesidad y tendencias del índice de masa corporal después de 6 años en el estudio de seguimiento en 
niños y adolescentes: el estudio de Cuenca. Med Clin (Barc) $\mathbf{1 1 9}$, 327-330.

Moreno LA, Sarria A, Fleta J, Rodriguez G \& Bueno M (2000) Trends in body mass index and overweight prevalence among children and adolescents in the region of Aragon (Spain) from 1985 to 1995. Int J Obes Relat Metab Disord 24, 925-931.

Powers CM, Lake JK \& Cole TJ (1997) Measurement and long term health risks of childhood and adolescent fatness. Int J Obes Relat Metab Disord 21, 507-526.

Rios M, Fluiters E, Perez Mendez LF, Garcia-Mayor EG \& Garcia-Mayor RV (1999) Prevalence of childhood overweight in Northwestern Spain: a comparative study of two periods with a ten year interval. Int J Obes Relat Metab Disord 23, $1095-1098$.

Rolland-Cachera MF, Deheger M \& Bellisle F (2001) Définition actuelle et évolution de la fréquence de l'obésité chez l'enfant. Cah Nutr Diét 36, 108-112.

Serra-Majem L \& Aranceta Bartrina J (2000) Desayuno y Equilibrio Alimentario: Estudio enKid. Barcelona: Masson.

Serra-Majem L, Ribas Barba L, Aranceta Bartrina J, Pérez Rodrigo C, Saavedra Santana P \& Peña Quintana L (2003) Obesidad infantil y juvenil en España. Resultados del estudio enKid (1998-2000). Med Clin (Barc) 121, 725-732.

Vanhala M, Vanhala P, Kumpusalo E, Halonen P \& Takala J (1998) Relation between obesity from childhood to adulthood and the metabolic syndrome: population based study. BJM 317, 319-320.

Wabitsch M (2000) Overweight and obesity in European children: definition and diagnostic procedures, risk factors and consequences for later health outcome. Eur J Pediatr 159, Suppl. 1, S8-S13.

World Health Organization (2000) Obesity: Preventing and Managing the Global Epidemic. Report of a WHO Consultation. WHO Technical Report Series no.894. Geneva: WHO.

World Health Organization (2004) World strategy on diet, physical activity and health. 57th World Health Assembly, 22 May. Geneva: WHO; available at http://www.who.int/gb/ebwha/ pdf_files/WHA57/A57_R17-en.pdf (accessed June 2004).

Yngve A, Poortvliet E \& Elmadfa I (2005) Intake of fruit and vegetables in a sample of 11-year-old children in 9 European countries: the Pro Children cross-sectional survey. Ann Nutr Metab 49, 236-245. 